\title{
Recurrent Bleeding From Ileal Conduit Stomal Varices in a Patient With Portal Hypertension
}

\author{
Jae-Wook Chung ${ }^{1, *}$, Yun-Sok Ha ${ }^{1, *}$, Jun Nyung Lee ${ }^{1}$, Tae-Hwan Kim¹, Tae Gyun Kwon ${ }^{1,2}$ \\ ${ }^{1}$ Department of Urology, School of Medicine, Kyungpook National University, Daegu, Korea \\ ${ }^{2}$ Joint Institute for Regenerative Medicine, Kyungpook National University, Daegu, Korea
}

\begin{abstract}
Bleeding from ileal conduit stomal varices is a rare complication. The standard treatment for the management of stomal varices has not been established yet. We present the case of a 65-yearold man with recurrent fatal bleeding from his ileal conduit stomal varices who was successfully treated with ligation of the engorged venous varices using hemostatic agents.
\end{abstract}

Key Words: Bleeding, Stoma, Varices, Portal hypertension
Received March 3, 2021

Accepted March 19, 2021

Corresponding author:

Tae Gyun Kwon

Email: tgkwon@knu.ac.kr

https://orcid.org/0000-0002-4390-0952

*These authors contributed equally to this study as co-first authors.

This research was supported by the Basic Science Research Program through the National Research Foundation of Korea (NRF) and was funded by the Korean Government (MSIT) (2016R1C1B1011180), (2019R1H1A1079839), and (2018R1C1B5040264).
Bleeding from ileal conduit stomal varices is uncommon and rarely reported. ${ }^{1}$ It can particularly develop in portal hypertension patients, and fatal massive bleeding from stomal varices can occur, ${ }^{2}$ making early detection crucial. This bleeding mainly occurs in enterostomal varices at the mucocutaneous borderline level. ${ }^{3}$ Management is challenging and varies from local treatment to shunting, embolization, and surgery. We present the case of a 65-year-old man with recurrent fatal bleeding from his ileal conduit stomal varices successfully treated with ligation of the engorged venous varices using hemostatic agents.

\section{CASE REPORT}

A 65-year-old man with massive ileal conduit stomal bleeding visited our Emergency Department. He underwent radical cystectomy with ileal conduit urinary diversion at another hospital in 2006. Three years previously, liver cirrhosis (severity of ChildPugh score B) was diagnosed. However, he did not receive any treatment for liver cirrhosis. Five months previously, he first experienced stomal bleeding during abdominal straining or coughing. He only observed this situation because the bleeding was tolerable after self-compression, and 2 months previously, massive bleeding of about

Copyright ( $\odot$ The Korean Urological Oncology Society and The Korean Prostate Society. All riguts reserved.

(i) (\$) This is an Open Access article distributed under the terms of the Creative Commons Attribution Non-Commercial License (http://creativecommons.org/licenses/ by-nc/4.0). which permits unrestricted non-commercial use, distribution, and reproduction in any medium, provided the original work is properly cited. 
800-1,000 mL per day occurred. He was admitted to the local hospital but only received transfusion of red blood cells and platelets.

At the Emergency Department, initial vital sign was stable but hemoglobin level was $7.7 \mathrm{~g} / \mathrm{dL}$ and platelet count $88 \mathrm{~K}$. Stomal bleeding emanated from the borderline at 6 o'clock between his ileal conduit and skin (Fig. 1). Transfusion was initiated, and abdominal computed tomography (CT) was performed. CT angiography showed parastomal cutaneous tortuous vessels connected to the mesenteric vessel, indicating a parastomal varix (Fig. 2). Radiologists were immediately consulted; however, angioembolization was not conducted because of difficulty in superselecting the bleeding venous varices and high risk of ileal conduit necrosis. Therefore, we performed operative management. Under local anesthesia, we dissected the area between the ileal conduit and parastomal skin. The engorged vessel with active bleeding was identified and ligated using nonabsorbable suture with absorbable collagen hemostatic agents.

Postoperatively, internal medicine doctors were consulted and liver cirrhosis management using ursodeoxycholic acid and diuretics was initiated. Follow-up duration was 18 months. Patient is free from stomal bleeding even when abdominal pressure rises.

This is a retrospective case report of single

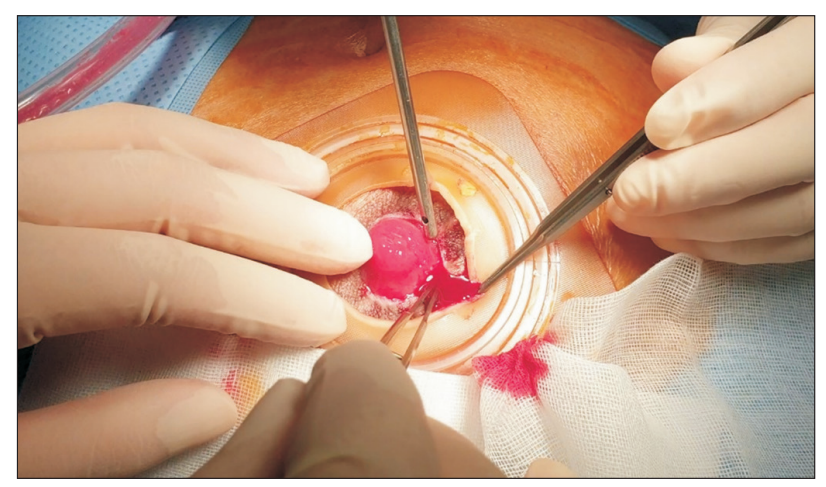

Fig. 1. Stomal bleeding emanating from the borderline at 6 o'clock between the patient's ileal conduit and skin. urology center. Present study was approved by the Institutional Review Board of Kyungpook National University, School of Medicine, Daegu, Republic of Korea (IRB No. KNUH 2020-05-009). This study was performed in accordance with the ethical standards laid down in the 1964 Declaration of Helsinki and its later amendments.

\section{DISCUSSION}

Ileal conduit stomal varices are rare. Studies on stomal varices are lacking, and most of these are case reports. ${ }^{4}$ Various conditions including calculi, infection, and cancer recurrence can cause ileal conduit bleeding ${ }^{5}$ and should be distinguished from ileal conduit stomal variceal bleeding. Stomal variceal bleeding can cause fatal massive blood loss; thus, prompt diagnosis and management are needed.

Typical varices, common liver cirrhosis complications, mostly develop in the gastroesophageal area. Ectopic varices can occur in the entire gastrointestinal tract, including the ileal conduit

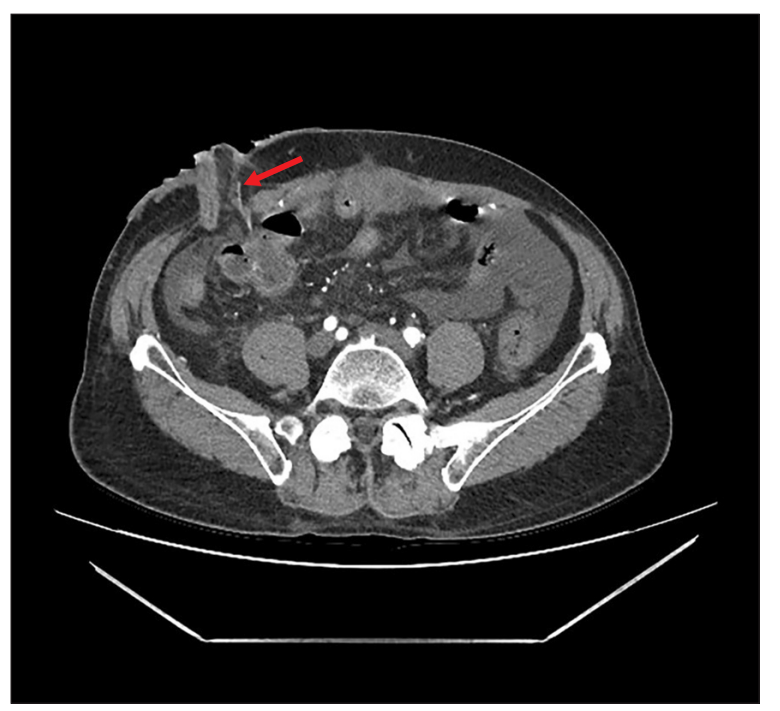

Fig. 2. Abdominal computed tomography angiography showing the parastomal cutaneous tortuous vessels (arrow) connecting to the mesenteric vessel, indicating a parastomal varix. 
stoma, accounting for approximately $5 \%$ of all variceal bleeding. ${ }^{1}$ High-pressure portal blood flow elevates variceal venous pressure of the stoma retrogradely; this elevated pressure is decompressed into a mucocutaneous venous network surrounding the stoma. ${ }^{6}$ Typical stomal bleeding on physical examination is observed in these mucocutaneous venous networks.

A standard treatment modality for stomal variceal bleeding is not established yet. A recent report recommended the consideration of various therapeutic approaches, including medical treatment, endoscopic management, ${ }^{7}$ intervention, surgical shunting, and liver transplantation. ${ }^{8}$ First, medical treatment for underlying portal hypertension should be performed. Conservative treatments, including local compression, bleeding vessel ligation, or sclerotherapy, may be considered but have a high recurrence rate of bleeding. In cases of continuous bleeding persisting even after initial treatment, endovascular embolization ${ }^{1,2,9}$ or transjugular intrahepatic portocaval shunt ${ }^{3,9,10}$ can be applied.

Urologists should be aware of the characteristics of ileal conduit stomal varices. Various therapeutic approaches should be considered, and a fundamental treatment for the causative disease should be developed.

\section{CONFLICT OF INTEREST}

The authors claim no conflicts of interest.

\section{REFERENCES}

1. Yao DH, Luo XF, Zhou B, Li X. Ileal conduit stomal variceal bleeding managed by endovascular embolization. World J Gastroenterol 2013;19:8156-9.

2. Onishi Y, Kimura H, Kanagaki M, Oka S, Fukumoto G, Otani T, et al. Successful embolization of ileal conduit stomal varices with N-butyl cyanoacrylate via a recanalized paraumbilical vein. Radiol Case
Rep 2018;13:1130-2.

3. Carrafiello G, Lagana D, Giorgianni A, Lumia D, Mangini M, Paragone E, et al. Bleeding from peristomal varices in a cirrhotic patient with ileal conduit: treatment with transjugular intrahepatic portocaval shunt (TIPS). Emerg Radiol 2007;13:341-3.

4. Oderda M, Mondino P, Lucca I, Fiorito C, Gillo A, Zitella A, et al. Fatal haematuria in a patient with an orthotopic neobladder and chronic liver failure. Urol Int 2009;83:368-9.

5. Lee SM, Yogan K, Carr T. Stomal varices: a cause for intermittent haematuria post-radical cystectomy. BMJ Case Rep 2016;2016:bcr2015214082.

6. Naidu SG, Castle EP, Kriegshauser JS, Huettl EA. Direct percutaneous embolization of bleeding stomal varices. Cardiovasc Intervent Radiol 2010;33:201-4.

7. Mitach A, Goris Gbenou M, Rashed S, Allegre JP, Ladhib Z, Lopez JG. Secondary recurrent haemorrhage with peristomal varices complicating a urinary derivation according to Bricker and treated efficiently by endoscopic way. Prog Urol 2012;22:127-31.

8. Helmy A, Al Kahtani K, Al Fadda M. Updates in the pathogenesis, diagnosis and management of ectopic varices. Hepatol Int 2008;2:322-34.

9. Kupczyk PA, Fischer S, Praktiknjo M, Stein J, Muller SC, Meyer C. Life-threatening bleeding from ileal conduit venous varices in a patient with portal hypertension. Urologe A 2019;58:41-4.

10. Medina CA, Caridi JG, Wajsman Z. Massive bleeding from ileal conduit peristomal varices: successful treatment with the transjugular intrahepatic portosystemic shunt. J Urol 1998;159:200-1. 